\title{
Entre inercias burocráticas y evaluaciones sobre las familias: adolescentes privados de libertad en Buenos Aires, Argentina
}

Between Bureaucratic Inertias and Evaluations of Families: Adolescents Deprived of Their Liberty in Buenos Aires, Argentina

Entre inercias burocráticas e avaliações sobre as famílias: adolescentes privados de liberdade em Buenos Aires, Argentina

\author{
MARINA MEDAN ${ }^{*}$ \\ Carla Villalta* \\ VALERIA LLOBET ${ }^{* * *}$
}

FECHA DE RECEPCIÓN: 30 DE NOVIEMBRE DE 2017. FECHA DE APROBACIÓN: 23 DE MAYO DE 2018

DoI: http://dx.doi.org/10.12804/revistas.urosario.edu.co/sociojuridicos/a.6309

Para citar este artículo: Medan, M.; Villalta, C. y Llobet, V. (2019). Entre inercias burocráticas y evaluaciones sobre las familias: adolescentes privados de libertad en Buenos Aires, Argentina. Estudios Socio-Jurídicos, 21(1), 293-326. Doi: http://dx.doi.org/10.12804/revistas.urosario.edu.co/sociojuridicos/a.6309

\section{RESUMEN}

Este artículo procura aportar a las discusiones en donde se intersecan asuntos relativos al gobierno poblacional con procesos de reproducción estatal de la desigualdad. Al analizar desde el punto de vista cualitativo expedientes judiciales sobre causas penales seguidas a adolescentes en Buenos Aires, en 2016, se enfoca en condiciones propias del sistema penal que refuerzan el uso de la privación de libertad sobre las poblaciones más vulnerables. El análisis socioantropológico de las prácticas estatales que aquí se propone aborda conjuntamente la dimensión material e interpretativa de las prácticas institucionales, así como las

* Doctora en Ciencias Sociales por la Universidad de Buenos Aires, investigadora del Consejo Nacional de Investigaciones Científicas y Técnicas, CONICET (Argentina) e investigadora en el Programa de Estudios Sociales en Infancia y Juventud del Centro de Estudios Desigualdad, Sujetos e Instituciones (CEDESI) de la Universidad Nacional de San Martín (UNSAM).

** Doctora en Antropología y Licenciada en Ciencias Antropológicas por la Facultad de Filosofía y Letras, Universidad de Buenos Aires. Investigadora del CONICET (Argentina) y co-coordinadora del Equipo de Antropología Política y Jurídica del Instituto de Ciencias Antropológicas, Facultad de Filosofía y Letras, UBA. Docente regular de la carrera de Ciencias Antropológicas (FF y L/UBA).

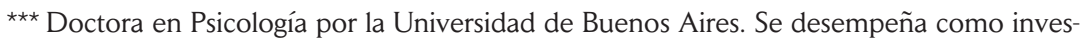
tigadora del CONICET en UNSAM, donde dirige proyectos de investigación y es docente de grado y posgrado. Codirige el CEDESI. 
formas en que se tramitan el género y la edad; además, reflexiona sobre el expediente como objeto constructor de realidades. El artículo argumenta que lo que configura las causas en las que se imponen medidas gravosas, como la privación de libertad -aun en un sistema penal especializado y acorde con los derechos humanos-, es una trama compleja entre las valoraciones morales de agentes judiciales sobre las trayectorias de los adolescentes y sus familias - previas y durante el tránsito por el sistema-, cómo las familias logran negociar esas interpretaciones y las inercias burocráticas que sofocan la garantía de derechos.

Palabras clave: sistema penal juvenil, privación de libertad, familia, desigualdad, derechos humanos.

\begin{abstract}
This article seeks to contribute to the discussions that intersect population government debates with processes of state reproduction of inequality. Analyzing judicial files of criminal cases followed towards adolescents in Buenos Aires in 2016, the paper focuses on the juvenile justice system's own conditions that reinforce the use of deprivation of liberty over the most vulnerable populations. The proposed analysis of the state practices includes both the interpretative and the material dimension of institutional practices, as well as the ways in which gender and age are processed; in addition, the paper reflects on the judicial file as an object that constructs realities. The article argues that what constitutes the causes in which the toughest measures such as the deprivation of liberty are imposed -even in a specialized penal system and in accordance with human rights-, is a complex interweaving between the moral evaluations of judicial agents on the trajectories of adolescents and their families, prior to and during transit through the system, how families negotiate these institutional interpretations, and the bureaucratic inertias that suffocate the guarantee of rights.
\end{abstract}

Keywords: Juvenile justice system, deprivation of liberty, family, inequality, bureaucracy.

\title{
RESUMO
}

Este artigo procura aportar às discussões que intersectam assuntos relativos ao governo populacional com processos de reprodução estatal da desigualdade. Analisando qualitativamente expedientes judiciais sobre causas penais seguidas a adolescentes em Buenos Aires em 2016, foca em condições próprias do sistema penal que reforçam o uso da privação da liberdade sobre as populações mais vulneráveis. A análise socioantropológica das práticas estatais que aqui se propõe aborda conjuntamente a dimensão material e interpretativa das práticas institucionais, assim como as formas em que se tramita o gênero e a idade; para além disso, reflete sobre o expediente como objeto construtor de realidades. $\mathrm{O}$ artigo argumenta que o que configura as causas nas que se impõem medidas gravosas como a privação de liberdade -ainda em um sistema penal especializado e acorde a direitos humanos-, é uma trama complexa entre as valorações morais de agentes judiciais sobre as trajetórias dos adolescentes e suas famílias, prévias e durante o transito pelo sistema. Como as famílias conseguem negociar essas interpretações, e as inercias burocráticas que sufocam a garantia de direitos.

Palavras-chave: sistema penal juvenil, privação de liberdade, família, desigualdade, direitos humanos. 


\section{Introducción}

"Lo que pasa es que afuera no hay nada, y las familias son muy lábiles", sostiene con decepción un juez de responsabilidad penal juvenil para explicar las razones de las altas tasas de prisionalización de jóvenes del departamento judicial de Buenos Aires en el que se desempeña (que a su vez ostenta las más altas de la provincia). Por ello, prosigue, es difícil morigerar las penas y optar por medidas alternativas. De esta manera, son el "afuera" y las "familias", como parte de esa "nada" que rodea la vida de los jóvenes que ingresan al sistema penal, los tópicos que se recortan como las razones más claras para explicar sus propias decisiones.

Ahora bien, isobre qué otras razones se traman las decisiones de adoptar una medida de privación de libertad de jóvenes acusados de cometer un delito? O bien, ¿cuáles son las condiciones institucionales que, presentes en el propio sistema y ya no "afuera", contribuyen a reproducir esas prácticas que provocan altos niveles de encarcelamiento de adolescentes y una sensación de frustración y de imposibilidad de idear otras alternativas en los funcionarios judiciales?

A partir de estos interrogantes, este artículo se inscribe en el campo de discusiones en donde se intersecan asuntos relativos al gobierno poblacional - tanto desde el Estado social como el penal- con los procesos de reproducción estatal de la desigualdad al enfocarse, para ello, en las prácticas institucionales. Específicamente, analiza las formas en que se administra el castigo para la población juvenil al identificar condiciones en las que el uso de las medidas privativas de libertad adquiere sentido como la intervención más eficaz y predominante y, por lo mismo, en las que se prolonga su duración.

De manera complementaria, el artículo procura aportar a los debates actuales que se producen en Argentina en el marco de las discusiones para la reforma del Sistema de Responsabilidad Penal Juvenil dentro de la cual se incluye la posibilidad de bajar la edad mínima de imputabilidad y punibilidad ${ }^{1}$.

1 Desde hace más de una década se discute en Argentina la necesidad de sancionar una ley de responsabilidad penal juvenil acorde a lineamientos de derechos humanos. En todos estos años han existido numerosos proyectos pero no se han alcanzado los consensos necesarios para sancionar una nueva norma (cfr. Guemureman, 2015). Sin embargo, a partir de la asunción de 
Los datos que informan nuestro argumento surgen principalmente de un relevamiento de expedientes judiciales de causas penales seguidas a adolescentes privados de su libertad en la provincia de Buenos Aires, Argentina. A partir de ello, se construyeron datos relativos al registro de los adolescentes y sus familias, las características de las causas y las acciones que se llevan a cabo como parte de su procesamiento judicial.

En la primera parte de este artículo se presentan las claves teóricas que informan la perspectiva de análisis, se detalla la estrategia metodológica enfocada en el trabajo con los expedientes y se describen el contexto normativo y el circuito institucional que recorren los jóvenes que ingresan al sistema penal. En seguida, dirigimos el análisis en torno a dos cuestiones: el papel de las familias y los "traslados" de los adolescentes privados de libertad. Explorar estas dimensiones de análisis, una que remite más específicamente a los aspectos interpretativos o socioculturales que orientan en todo momento la gestión judicial de los adolescentes, y otra que refiere a la dimensión material de las prácticas burocráticas que se despliegan en torno a ellos y sus familias - caracterizadas por inercias burocráticas, desidia, pero también por la rutinización de la administración- puede echar luz sobre las condiciones socioinstitucionales que contribuyen a sostener elevadas tasas de prisionalización. El artículo termina con una discusión sobre la forma particular que adquiere la administración de la justicia penal juvenil a la luz de las múltiples interpretaciones coexistentes sobre las causas del delito juvenil, la finalidad del encierro y las vías de reinserción social, así como las inercias burocráticas que sofocan los intentos por garantizar derechos.

\section{La administración estatal: procesos de categorización, interpretación $y$ maniobra}

Tradicionalmente, la relación del Estado con las nuevas generaciones ha sido ambigua y se ha caracterizado por sostener al mismo tiempo, y en tensión, objetivos vinculados al cuidado y a la inclusión social junto Mauricio Macri como presidente, en 2015, estos debates se han radicalizado como parte de una
concepción política que privilegia el discurso de la seguridad sobre el de los derechos humanos y,
oficialmente, se propone bajar la edad de imputabilidad/punibilidad (actualmente en dieciséis años). 
con otros de control y sanción. Esto ha supuesto que tanto las normativas como las políticas sociales y sociopenales hayan inclinado más el peso de esta tensión hacia construcciones de un sujeto en riesgo que, dependiendo del enfoque, requiere protección y reencauzamiento, o control y sanción (Villalta, 2013). Los modos en los que, en cada contexto sociohistórico, el problema de la "juventud en riesgo" o la "criminalidad juvenil" es configurado como un tipo de problema social que dará origen a específicas intervenciones, tramas institucionales y formas de administración, han sido objeto de debate, en especial a partir de la incidencia de la Convención de Derechos del Niño en el ámbito local. Así, numerosos estudios señalaron la eficacia de los modos de control social desplegados en la institucionalidad para "menores" creada a inicios del siglo XX y recreada o reformada con posterioridad (García Méndez E Beloff, 2004; Guemureman \& Daroqui, 2001). La eficacia de ideologías clasistas y autoritarias que producían una segregación institucional entre niños y menores, a la vez que la persistencia de prácticas discresionales y normalizadoras (Guemureman, 2010; Daroqui, et al., 2012) han tendido a ser las dimensiones dominantes en estos debates.

Desde la perspectiva que queremos colocar aquí, el eje en la homogeneidad de los dispositivos de intervención, ya sea en su eficacia moral, en las prácticas de subjetivación, o en el ejercicio de la adminstración de justicia como un cuerpo homogéneo, no permite considerar en su totalidad los matices, las controversias y los conflictos que hacen de las prácticas institucionales una trama compleja. A su vez, dificulta analizar los discursos e ideas institucionalizados al capturar su multiplicidad. Así, aquí interesa evitar la reificación del Estado como entidad monolítica y unificada y ubicar el análisis, antes bien, en las prácticas penales históricamente variables y situadas, a la vez que traspasar los límites de lo estatal para integrar al análisis las prácticas y negociaciones de los actores "externos" (Biebricher, et al., 2012).

El Estado es, así, un ente multidimensional, dispuesto en capas y compuesto de aparatos que actúan de forma no siempre coherente. A la vez, al seguir este supuesto, no es teóricamente productivo suponer la institucionalización homogénea de un discurso unívoco (Haney, 1996; 2002). En primer lugar, porque el Estado es, ante todo, intérprete, y en cada arreglo institucional específico estipula necesidades y demandas legítimas 
(Fraser, 1991). La dimensión interpretativa del Estado supone procesos de construcción y categorización de sujetos, asignación de características asociadas a estos y modos de comportamientos esperables de clase, edad y género. Este conjunto de procedimientos está configurado por cláusulas subjetivas de inclusión, tras las cuales suceden procesos de legitimación, naturalización y producción de la exclusión y reproducción de desigualdades sociales - de clase, de edad, de género-(Llobet, 2013).

La edad, en nuestro planteo, es específicamente significativa pues un ordenador burocrático, en las sociedades con Estado, la hace aparecer vinculada a la idea de neutralidad (Mintz, 2008). En este sentido, el principio de especialidad en la justicia penal juvenil legitima al Estado para intervenir como garante de derechos con una direccionalidad específica al tiempo que invisibiliza el hecho de que sus prácticas "protectivas" son, en efecto, prácticas de poder. No solo sobre los adolescentes, sino también sobre sus familias. En efecto, en el tratamiento del delito atribuido a adolescentes, las familias son interpeladas por el Estado a jugar un papel responsable y adulto, al tiempo que se las minoriza e incapacita (Vianna, 2010) para legitimar su desplazamiento momentáneo como garantes de la tutela de los adolescentes a quienes se priva de libertad. La familia no solo es evaluada y juzgada, sino también construida por el Estado a través de los mensajes prescriptivos y coactivos que emanan de este tipo de órganos y de los profesionales que los componen (Bourdieu, 1998).

Por otro lado, el sistema penal -y sobre todo el juvenil- es, además de clasista, generizado, en tanto persigue y pena los delitos atribuidos a varones ${ }^{2}$. A su vez, el modo en que se gestiona el delito juvenil se encuentra informado por particulares asociaciones entre masculinidad, riesgo y delito 3 .

2 El 95,81\% de la población privada de libertad en Argentina, en 2015, era masculina (Sistema Nacional de Estadísticas sobre Ejecución de la Pena, www.jus.gob.ar).

3 Otros trabajos han mostrado cómo la construcción social del riesgo en programas de prevención del delito juvenil es diferencial según género (Medan, 2011). Dado que en nuestra muestra no existían causas seguidas a mujeres, no podemos determinar si las reglas de conducta que se les imponen a los varones difieren de las que se aplican sobre ellas. Sin embargo, la prohibición de salidas nocturnas, de consumo de alcohol y sustancias, de relacionarse con ciertos grupos de pares, de entrar en contacto con la víctima, así como la petición a los progenitores de los jóvenes de velar por el cumplimiento de estas reglas, parecen todas exigencias propias de una interpretación sobre las causas del delito masculino que lo asocia a la exposición al riesgo en el espacio público y a conflictos y violencia en relaciones interpersonales. 
Ahora bien, estos procesos interpretativos al interior del Estado no son lineales. Varios trabajos sobre procesos de institucionalización de derechos han mostrado que, desde los cambios normativos a las transformaciones en las prácticas y culturas institucionales, no hay ni un canal directo, ni una ruptura necesaria (Fonseca \& Schuch, 2009; Villalta, 2010). Esto sería propio de "una visión normativa que lleva a olvidar que el derecho, para ser transformador, debe estar acompañado de diferentes grados de consenso social y de prácticas y acciones que lo modelen y le den vida" (Villalta \& Llobet, 2015).

En un segundo nivel, estas interpretaciones informan arquitecturas particulares de necesidades y establecen qué sujetos acceden a qué derechos, en qué términos y quiénes quedan fuera de ellos, delimitando esferas de distribución y también de reconocimiento (Fraser, 1991; Haney 2002). Con base en esta arquitectura, el Estado, a través de sus políticas sociales y penales, produce distintos mensajes que envía a la población que regula, mensajes que en ocasiones son contradictorios (Haney, 1996; Medan, 2014). Esto no se entiende como una "falla" de un "sistema" idealmente homogéneo, ni como un efecto "perverso" necesariamente, sino como una característica propia de un tipo de regulación que Lynne Haney ha denominado "gobierno por contradicción" (Haney, 2004) que funciona tanto en políticas sociales como en políticas penales. Esto supone que existe una diversidad de prácticas institucionales y que los sujetos son gobernados por la ambigüedad y la contradicción, quedando atrapados en las inconsistencias propias del sistema. Ello no supone desligar al Estado de sus responsabilidades como garante de derechos. Sin embargo, sí requiere que al examinar el Estado y sus formas de regulación le quitemos el halo de sistematicidad y de accionar totalizante que en ocasiones se le asigna. Este opaca tanto los discursos en disputa que coexisten y pelean por la hegemonía, como las consecuencias de su accionar. Desde esta perspectiva, y tal como otras investigaciones sobre dispositivos penales han mostrado (Haney, 2010; Schuch, 2009), podremos advertir que en la justicia penal juvenil coexisten discursos que en apariencia podrían ser contradictorios, pero que operan simultáneamente en tanto que, mientras procuran construir un sujeto responsable de sus acciones y autónomo en su resocialización, consideran el accionar y la configuración de sus familias - en tanto menor que debe ser cuidado- 
el principal determinante para las decisiones penales a adoptar sobre el joven $\mathrm{y}$, como consecuencia, la clave para administrar el acceso a derechos de los jóvenes.

En un tercer plano, desde esta perspectiva de análisis, es posible considerar cómo, en el seno de las múltiples y contestadas interpretaciones que le dan forma a las prácticas burocráticas y a la arquitectura de necesidades, existe un espacio de maniobra para los sujetos (Haney, 2002) en el terreno de las interacciones. De hecho, incluso a partir de la lectura de los expedientes judiciales es posible advertir cómo los adolescentes y sus familias negocian - aun en condiciones de desventaja- las interpretaciones que sobre ellos hacen los agentes judiciales.

El aporte de tales estudios sobre el Estado y las prácticas burocráticoinstitucionales que enfatizan en los procesos simbólico-culturales y relacionales que estructuran el campo de intervención y orientan las acciones, definiendo las demandas legítimas y los sujetos que las enuncian, contribuye a iluminar las dinámicas concretas de exclusión y jerarquización en su variabilidad histórica (Bourdieu, 1994; Fraser, 1991).

Así, en una compleja composición, no siempre diáfana en sus elementos interpretativos, espacios de maniobra, y también por sus condiciones de funcionamiento en apariencia más objetivas y rutinarias, el Estado se analiza en tanto espacio desde donde se construyen procesos de inclusión y exclusión social reproduciendo, en muchos casos, desigualdades. Por ejemplo, la imposición de medidas penales más gravosas a los sujetos más vulnerables.

Desde esta perspectiva, este artículo busca aportar a la comprensión sobre las formas en las que las configuraciones institucional y sociocultural de la justicia penal juvenil inciden en la gestión de la desigualdad social. Es decir, procuramos analizar a través de qué microprácticas ese tratamiento desigual (que implica que el peso punitivo del Estado sea mayor en los sectores más vulnerables) se reproduce y transforma, en qué procedimientos - que por lo general general permanecen opacos- se asienta, y cómo tales prácticas son negociadas por los distintos actores. Para ello, analizamos dos dimensiones que resultan significativas en las formas de administrar justicia penal a los adolescentes: las interpretaciones sobre el papel que les cabe a las familias en los modos en que se producen las 
causas y las rutinas burocráticas propias de la gestión de adolescentes en situación de privación de libertad.

\section{Metodología}

\section{Sobre la producción de los datos}

Este estudio se enmarca en el campo de investigaciones que se preguntan por las transformaciones de las políticas sociales y socio penales para niños y jóvenes. Específicamente, los datos que aquí se analizan surgen de un relevamiento que buscó caracterizar a jóvenes y su tránsito por el sistema penal en el contexto de preocupaciones de efectores públicos de una localidad del Gran Buenos Aires sobre la situación de los adolescentes privados de libertad y la evolución de sus causas en un contexto descrito como de alta tasa de prisionalización y de escasa aplicación de medidas alternativas al encierro tanto por falta de recursos en la comunidad, como por la "labilidad" de las familias. El relevamiento en cuestión se realizó entre noviembre de 2015 y octubre de $2016^{4}$.

El contexto de colaboración interinstitucional en el que se desarrolló dicho relevamiento, entre el equipo de investigación y los efectores locales encargados de implementar políticas sociales y sociopenales, permitió el acceso a los datos y mejoró las posibilidades de triangulación de fuentes (expedientes, entrevistas y observación participante de reuniones interinstitucionales), a la vez que, luego del análisis, permitió la validación de los datos.

\section{El expediente judicial como un objeto socialmente construido}

La investigación se centró fundamentalmente en el relevamiento de los expedientes judiciales que se originan a partir de la causa judicial

4 La extensión de este trabajo no permite desplegar el hecho de que este diagnóstico encarado desde un órgano de participación local fue la plataforma desde la que cierto activismo judicial pudo relocalizar intereses y las demandas que, en el propio contexto judicial, no gozaban de una posición dominante. La investigación supuso un informe final que fue discutido con miembros del Consejo Local y con actores involucrados en el tema. 
que se les abre a los jóvenes acusados de cometer un delito 5 . En total se relevaron 26 expedientes que involucraban a 28 adolescentes que fueron procesados por los delitos que en la tabla que sigue se detallan ${ }^{6}$.

Tabla 1. Detalle de la muestra y carátula de las causas

\begin{tabular}{|l|c|c|}
\hline \multicolumn{3}{|c|}{ Expedientes y jóvenes } \\
\hline Cantidad de expedientes & \multicolumn{2}{c|}{26} \\
\hline Cantidad de jóvenes involucrados & \multicolumn{2}{c|}{28} \\
\hline \multicolumn{1}{|c|}{ Tipo de delito } & Consumado & Tentativa \\
\hline Homicidio & 3 & 2 \\
\hline Robo simple & 2 & 0 \\
\hline Robo con arma apta (fuego y blanca) & 9 & 0 \\
\hline Robo con arma no apta (o de utilería) & 2 & 2 \\
\hline Robo en banda & 2 & 1 \\
\hline Secuestro & 1 & 0 \\
\hline Lesiones & 2 & 0 \\
\hline Total & 21 & 5 \\
\hline
\end{tabular}

Fuente: Elaboración propia.

Los criterios de inclusión de los expedientes en la muestra fueron: a) que tuvieran como imputados a adolescentes privados de la libertad al 31 de marzo de 2016, momento de inicio del relevamiento; b) que los adolescentes residieran en la localidad para la que se realizaba el relevamiento ${ }^{7}$; c) que fueran causas elevadas a juicio y tramitadas en uno de los juzgados del distrito ${ }^{8}$.

5 Además se realizaron seis entrevistas en profundidad a agentes judiciales.

6 En el momento del relevamiento eran 300 las causas con adolescentes privados de la libertad procedentes de todas las localidades bajo incumbencia del Departamento Judicial, repartidas equitativamente entre cada uno de los tres juzgados. Así, el juzgado en el que hicimos el relevamiento tenía bajo su órbita 100, de las cuales las 26 relevadas correspondían a la localidad que teníamos en estudio.

7 Cada Departamento Judicial tiene incumbencia sobre varias localidades (en este caso cinco) y el relevamiento se ciñó a adolescentes con residencia en aquella desde la que había sido motorizada la investigación.

8 La elección del juzgado se rigió por criterio de factibilidad para acceder a los expedientes. Las causas se asignan pareja y aleatoriamente a los juzgados existentes en el Departamento 
Para contextualizar la información obtenida es necesario considerar que un expediente judicial es, en el ámbito tribunalicio, un artefacto clave de la gestión burocrática. Construido a través de la técnica de la escritura, es polifónico, en tanto se compone de documentos diversos (tales como oficios, autos de procesamiento, resoluciones, informes socioambientales, entre otros) que han sido elaborados por los distintos agentes que modelan el circuito que los jóvenes recorren. Así, lo que aparece en el expediente son determinados hitos de la administración que toman la forma de audiencias, resolución de pedidos, informes y resoluciones judiciales, tras las que se suceden distintas acciones, ya sea de convencimiento, de amenaza o de acuerdos entre los diferentes actores que, en tanto no se encuentran reflejados en la materialización burocrática de la intervención, deben ser inferidos y leídos entre líneas.

En efecto, tanto para dar cuenta de la tarea realizada, como para rendir cuenta a los superiores, el expediente ocupa un lugar central en la administración judicial de conflictos y no reconstruye los hechos tal como sucedieron, sino que se trata de un conjunto de relatos y de versiones sobre los conflictos que permiten convertir los hechos sociales en hechos judiciables (Martínez, 2004; Sarrabayrouse Oliveira, 2011; Eilbaum, 2005; Muzzopappa \& Villalta, 2011). Por eso, el expediente nos informa más sobre la lógica tribunalicia que lo estructura que sobre las características de los hechos y las personas sobre las que versa.

Por ello los expedientes judiciales representan un material que ofrece una valiosa información, por un lado, para comprender qué es lo considerado legítimo en el ámbito judicial para construir versiones verosímiles de los hechos (Eilbaum, 2005) y por otro, para identificar semblanzas de las personas que explican y, en buena medida, también justifican la adopción de distintas medidas por parte de los agentes judiciales. Es decir, nos permiten analizar la mirada que sobre los adolescentes, sus familias, sus barrios y los delitos que se les imputan construyen y reconstruyen los diferentes agentes que participan en el proceso penal. También, qué es lo que dicha mirada en este ámbito habilita y legitima, ya sea la privación

Judicial, por lo que no existe sesgo en el tipo de causas relevadas. No obstante, una vez que están bajo determinado juzgado, las intervenciones realizadas pueden tener la impronta del juzgado particular que las gestione. 
de libertad, la extensión en el tiempo de esta medida, la posibilidad de egreso, el trabajo con la familia del adolescente, etcétera.

Asimismo, el expediente da pistas del sustrato de relaciones que sostienen el circuito que recorren los jóvenes. Relaciones que, en este objeto material de la administración, toman la forma de comunicaciones, oficios, pedidos, informes o vistas. Así, las comunicaciones con la Policía o con los institutos donde están alojados los jóvenes y los pedidos que el juzgado realiza a los peritos sociales o psicológicos se transforman en indicios para reconstruir la trama de relaciones que compone la justicia penal juvenil.

Desde esta perspectiva, el expediente condensa la heterogeneidad que es propia del Estado; las múltiples interpretaciones que coexisten dentro de este de un modo, en ocasiones, contradictorio; los distintos discursos (jurídicos, sociales, psicológicos) que dan forma a la construcción de sujetos y su gobierno. De igual forma, el expediente muestra parte de una de las facetas más opacas del Estado, aquella que funciona (o no) sin precisión, ni direccionalidad, ni deliberación, sino más vale formas "contingentes" (Guemureman, 2010) y/o por inercias burocráticas. Inercias cuyos efectos pueden ser devastadores para los sujetos que las padecen, aunque por el tipo de sujetos que son -jóvenes varones de sectores populares, "delincuentes", "peligrosos" - no son visibles ni llegan a problematizarse.

Ahora bien, antes de adentrarnos a la construcción de "realidad" que proveen los expedientes, es preciso inscribir su producción en el Sistema de Responsabilidad Penal Juvenil Vigente y a este en su historicidad.

\section{Resultados: gestionando el encierro}

\section{El Sistema de Responsabilidad Penal Juvenil en funcionamiento}

En Argentina, uno de los hitos más significativos ocurrido en los últimos años en relación con la justicia penal juvenil fue la sanción de una normativa que vino a saldar el prolongado debate sobre las atribuciones judiciales que tendían a la protección de los derechos de los niños y/o a su castigo. Con la sanción de la Ley 26061 (de 2005), Argentina alineó 
parte de su normativa a la Convención de los Derechos del Niño y derogó la Ley de Patronato por la que la justicia intervenía, indistintamente, en causas penales o asistenciales seguidas a menores de edad, y los jueces de menores tenían la facultad de "tutelar" hasta la mayoría de edad a los niños/as y jóvenes que se encontraran -según la evaluación de los funcionarios - en una situación de peligro moral y/o material.

Ahora bien, a pesar de la sanción de esta ley en materia de protección integral de la infancia, de acuerdo a un enfoque de derechos humanos, en Argentina sigue vigente un régimen penal de la minoridad que no se adecúa a los estándares internacionales a los que el país adhiere (no es especializado, ni posee garantías sustanciales, ni procesales, no considera la privación de libertad como último recurso, ni prevé medidas alternativas al proceso penal) (UNICEF, 2008). En efecto, la normativa de fondo todavía es el Decreto-Ley 22.278 de 1980, claro exponente del denominado "derecho de menores" (Beloff, 2004) y, como tal, objeto de diferentes críticas en tanto habilita una práctica judicial reñida con los principios de derechos humanos.

Sin embargo, el carácter federal del país ha permitido que, aun con esa normativa de fondo, las legislaciones provinciales hayan podido adecuar sus sistemas morigerando, en parte, los aspectos más "tutelares" o más violatorios del debido proceso que encierra aquella norma. Este es el caso de la provincia de Buenos Aires que, en 2007, luego de un conflictivo proceso, sancionó la Ley 13.298 (de promoción y protección integral de los derechos de los niños) y la Ley 13.634 (principios generales del fuero de familia y fuero penal del niño). El largo proceso de reforma y la creación del Fuero de la Responsabilidad Penal Juvenil (FRPJ) permite constatar que la separación social-penal no estuvo exenta de conflictos. La reforma estuvo rodeada, antes y después de sancionarse la ley, de una serie de cuestionamientos y discusiones, sobre todo, en relación con el poder omnipresente del juez de menores, la arbitrariedad y la discrecionalidad de las decisiones, la amplitud de los alcances de las competencias entre materias penales y sociales, etcétera (López, 2010). En gran medi$\mathrm{da}$, estas discusiones llevaron a construir un sistema que, para centrarse en proveer garantías de debido proceso a los adolescentes - propias del fuero penal de adultos y del derecho penal de acto- terminó por parecerse cada vez más al sistema penal de mayores. Además, la anhelada 
separación de las problemáticas de índole penal de las de origen social implicó, en algunos casos, la no intervención social sobre causas penales.

Ahora bien, más allá de las discusiones a su alrededor, la Ley 13.634 crea un fuero específico y especializado en materia de responsabilidad penal juvenil cuyos principios rectores, de acuerdo a un enfoque de derechos humanos, son "la protección integral de los derechos del niño, su formación plena, la reintegración en su familia y en la comunidad, la mínima intervención, la subsidiariedad, la solución de los conflictos y la participación de la víctima" (Artículo 33). A partir de la sanción de esta normativa comenzó un proceso de rediseño de la justicia juvenil que implicó el remozamiento de los antiguos juzgados de menores bonaerenses que tenían una amplia competencia que desbordaba la estrictamente penal y cuya creación databa de 1938. Este rediseño implicó el desdoblamiento de esos tribunales en juzgados de garantías y de responsabilidad penal juvenil, la creación de nuevos juzgados, así como de fiscalías y defensorías especializadas, y de un Cuerpo Técnico Auxiliar (CTA), formado por médicos, psicólogos y trabajadores sociales. Así, a partir de la sanción de esta normativa, nuevos actores fueron llamados a intervenir y se inauguraron también nuevos circuitos.

\section{Circuitos y actores intervinientes}

¿Qué circuitos recorren los jóvenes acusados de cometer un delito? ¿Cómo, quiénes y con qué atribuciones están llamados a intervenir en la gestión del delito juvenil? La intervención del FRPJ puede iniciarse con la denuncia de un particular en la Fiscalía, o cuando la Policía aprehende a un adolescente e informa al agente fiscal. Con la información policial (sobre el tipo de delito imputado y las circunstancias), y luego de constatar si existen registros previos, el fiscal define si inicia una investigación penal preparatoria (IPP). Si decide no iniciarla puede indicar la libertad y no hacer ninguna otra intervención, pedir evaluaciones complementarias al CTA, o indicar la libertad pero citar al adolescente y a su familia para, eventualmente, derivar el caso al Servicio de Protección de Derechos?. 
Si inicia la investigación, da intervención a la defensa, al juzgado de garantías y puede ordenar la libertad y citación, o pedir la detención. Usualmente pide que el CTA entreviste al joven y/o a su familia en relación con su trayectoria vital, educativa, sanitaria, laboral y sus condiciones de vida. Con esta información, los peritos elaboran un informe en el que valoran al joven y/o su familia; dicho material constituye un insumo central para que el fiscal solicite y el juez convalide o decida la medida a tomar (por ejemplo, privación de libertad o medidas cautelares en libertad).

Si la decisión adoptada por el juez de garantías es que el joven continúe en libertad, puede imponerle otras medidas como la prohibición de salir de ciertas jurisdicciones, de participar en ciertos eventos o de contactarse con ciertas personas, y la obligación de concurrir periódicamente al Tribunal y de cumplir una serie de reglas de conducta $^{10}$. Si en cambio se adopta una medida cautelar de privación de la libertad, el joven será derivado a dispositivos especializados de régimen cerrado o semicerrado dependientes del área de niñez provincial. La duración de la medida de privación de libertad no está pautada de antemano: dependerá mucho del momento de realización del juicio (que puede ser un juicio convencional o abreviado). A su vez, los defensores pueden solicitar cada tres meses audiencias de revisión de las medidas. En ellas, el juez evalúa, a partir de los informes aportados por los equipos técnicos de los dispositivos de encierro y de los elaborados por el CTA sobre el adolescente y su familia, si se encuentra en condiciones de egresar o no.

Cuando la investigación ha finalizado, se pide la elevación a juicio. Como parte de la especialidad del fuero y de las normas de fondo vigentes, es posible que el juicio se divida en dos: en una primera parte se dicte el auto de responsabilidad, se imponga una serie de medidas de integración social (tales como orientación y apoyo sociofamiliar, reparación del daño, servicios comunitarios, asistencia especializada, inserción escolar, inclusión prioritaria en los programas estatales de reinserción

en esa decisión la información provista por la Policía que es, además, el primer eslabón en la selección de la criminalidad (Saín, 2015) y una figura central en la experiencia cotidiana de jóvenes -en especial de los varones- sobre los que despliega prácticas violentas y de hostigamiento (Cels, 2016).

10 Estas medidas son supervisadas por programas de acompañamiento en territorio dependientes del área de niñez provincial. 
social o protección de derechos, imposición de reglas de conducta), y se prorrogue la imposición de pena hasta tanto se cumpla la mayoría de edad además de un año de cumplimiento de estas medidas. Esto implica que, transcurrido ese tiempo, se llegue a la segunda parte del juicio, la de cesura, y si el juez entiende que los objetivos del fuero relacionados con la resocialización y reeducación (Villalta, 2004; Schuch, 2009; Lugones, 2012) se cumplieron, no aplique pena.

En definitiva, una vez que el joven es privado de su libertad, el camino hacia recuperarla depende en gran medida de los informes que el CTA, los equipos técnicos de institutos de encierro y los demás actores judiciales elaboren sobre cómo consideran su evolución y la de su familia por el sistema penal; de estos informes también dependerá qué pena se le aplique. En este circuito, adolescentes y familias se encuentran con diferentes organismos y agentes cuyo accionar está pautado y detentan distintos saberes prácticos y científicos con los que informan las diferentes prácticas burocráticas en relación con ellos. Pero también encarnan diferentes posturas e interpretaciones acerca de los adolescentes, sus presuntos delitos y sus contextos. En efecto, el sistema penal, como parte de la administración burocrática del Estado, también dista de ser monolítico y homogéneo.

\section{Sobre las causas y el contexto social y familiar de los adolescentes}

En su mayoría los expedientes trataban, según la carátula, de "robo con arma". Los seguían, "homicidio". La mitad de los adolescentes imputados contaba con entre 0 y 1 IPP (Investigación Penal Preparatoria) previa ${ }^{11}$. Este dato es opaco y conlleva preguntas alrededor de, o bien la "dureza" del sistema que con ninguna o solo una causa anterior utiliza la privación de libertad como primera medida, y/o de si existe una trayectoria anterior de contacto de los adolescentes con el sistema penal que no se registra y sobre la que no se sabe cómo sus diferentes organismos intervienen, en particular, la Policía. De los 28 adolescentes incluidos en los expedientes, sobre 24 se pudo reconstruir cuánto tiempo llevaban privados de su

11 Esto es, los adolescentes no habían sido investigados por ningún o solo por un único delito cometido previamente al delito por el cual tuvieron una pena privativa de libertad. 
libertad al momento del trabajo de campo. En promedio llevaban 2 años y 2 meses; mientras el que menos tiempo había permanecido preso lo estaba desde hacía 7 meses, el que más llevaba tenía 5 años y 10 meses.

Todos los adolescentes de la muestra eran varones. Para la mayoría, el máximo nivel educativo alcanzado era sexto o séptimo grado incompleto, en un tercio de los casos hay señalamientos de repitencias y/o deserciones y todos los que estaban escolarizados lo hacían con sobreedad. A su vez, todos provenían de familias cuyos ingresos surgían de ocupaciones informales y precarias y de asistencia estatal. A partir de los expedientes se tuvo conocimiento de la ocupación de 37 progenitores. En su mayoría, las madres se dedicaban al servicio doméstico ( 9 mujeres), y los padres eran choferes (6 casos). Además, 5 padres eran empleados en fábricas o en el municipio (realizando recolección de residuos), 5 madres amas de casa, 4 progenitores señalaron cobrar planes sociales, 3 padres se desempeñaban en la construcción, 2 obtenían ingresos a través de la recolección de cartones, 2 como cuentapropistas reparando electrodomésticos y 1 señaló que obtenía ingresos mediante ocupaciones esporádicas ("changas").

La muerte de familiares jóvenes, así como la violencia y el delito, eran parte de la configuración de muchas de las familias de los adolescentes. Según los expedientes, en 22 casos constan situaciones previas de violencia y de muertes por causas externas en el entorno del adolescente que, en mayor o menor medida, están asociadas al delito que se le imputa (entre pares, vecinos, violencia familiar y de género, familiares presos, y familiares muertos o en la cárcel o en enfrentamientos o por la policía). En 10 casos constan muertes por causas no relacionadas a la salud en el grupo familiar primario, usualmente hermanos, y 4 adolescentes tenían hermanos presos.

Además, todos los jóvenes habitaban en los barrios más vulnerables de la localidad y un tercio residía en un mismo barrio, conocido por su extrema pobreza, por deficiencias infraestructurales y por la presencia de redes delictivas. El contexto era de precariedad de la calidad de vida, y de fragilidad y vulnerabilidad en la experiencia vital ${ }^{12}$.

12 Del conjunto de los expedientes fue posible componer un panorama bastante homogéneo de los contextos sociales y familiares en donde vivían los adolescentes implicados. Su 


\section{Negociaciones entre agentes judiciales y familias, las responsables del encierro y del egreso}

Una de las cuestiones que sobresale en los expedientes es el papel de las familias de los adolescentes implicados y la centralidad que ocupan como blanco de interpelación. En efecto, la familia del joven es a quien primero se cita, a quien se evalúa para decidir si llevar o no adelante el proceso penal, a quien se observa para ponderar si es necesaria una medida de privación de libertad o si, por el contrario, el joven está en condiciones de cumplir una medida cautelar en libertad. También, el comportamiento que tenga la familia y la clase de familia que sea resulta central para lograr el egreso del joven privado de la libertad. La familia pareciera transformarse, así, en principio explicativo de todo lo que acontece en este ámbito (Villalta, 2004).

Además de que esto ocurre en la práctica judicial, el papel de las familias es expreso en la ley: uno de los objetivos principales del fuero es la reintegración de los adolescentes a sus familias, y la primera medida de integración social es la orientación y el apoyo social a la familia para que intervenga en el cumplimiento del proceso de integración social (Artículos 68, 69, 74 y 78).

Al nivel de la práctica de la administración de justicia se advierte que, además de clave en la reintegración de los adolescentes, las familias y lo que hayan hecho o no en el pasado las constituye también como las responsables de las situaciones que llevan a los adolescentes al conflicto con la ley. Esto es visible en las caracterizaciones que sobre ellas hacen las peritos psicólogas y trabajadoras sociales del CTA al entrevistar a los jóvenes o a sus progenitores, tanto a partir de los hechos que los primeros cuentan sobre sus familias, como de la interpretación de los peritos de las actitudes familiares.

Las caracterizaciones dominantes podrían dividirse entre, por un lado, las que se refieren a la falta de idoneidad de padres o de madres respecto del papel adulto ideal en la crianza de los niños y/o adolescentes.

\footnotetext{
vida cotidiana y la de sus familias estaba caracterizada por el escaso, deficitario -y a veces hasta suspendido- acceso a derechos laborales, educativos, sanitarios, habitacionales, todo lo que redundaba en trayectorias institucionales infructuosas y en relaciones interpersonales donde el uso de la violencia o la muerte temprana eran moneda habitual.
} 
En palabras de agentes judiciales, las familias "no han podido o sabido cuidar". Son familias "poco contenedoras", con "dificultades de contención y efecto", con "organización familiar endeble" cuyo papel adulto está "desdibujado". Así, las pericias minorizan a las familias (Vianna, 2010) y se refieren a sus experiencias como "fallidas en su rol adulto".

Por otro lado, podrían agruparse caracterizaciones que se refieren a familias "que no han querido" cuidar u orientar adecuadamente. Familias que, según los actores judiciales, tienen una actitud "negadora" respecto de los problemas de sus hijos, que naturalizan el contexto de violencia en el que viven y no dimensionan de manera apropiada el carácter negativo, transgresor y delictivo de las acciones de los adolescentes. Estas familias también pueden ser calificadas como "no implicadas"13.

Estas caracterizaciones suponen valoraciones morales de las familias que pueden incluso no tener ninguna relación con el delito que se le imputa al adolescente. Por ejemplo, el señalamiento de que "todos los hijos de la madre son de distinto padre". Tal como otras investigaciones han mostrado (Vianna, 2010; Guemureman, 2010), este tipo de valoraciones que aparecen cristalizadas en el expediente para que otros las lean, para informar, pero también para formar opinión, inciden en el devenir de las causas. En los expedientes se advierte lo vinculantes que estos informes son para la toma de decisiones de fiscales y jueces, así como para la elaboración de las estrategias de los defensores. En efecto, en las sentencias se citan, textualmente, fragmentos de estos informes para legitimar las posiciones tomadas que, en muchos casos, suponen medidas gravosas como la privación de libertad.

$\mathrm{Si}$, como señalamos antes, las interpretaciones sobre las necesidades dan forma a lo que es posible en el nivel distributivo y la arquitectura de las necesidades es informada por estas interpretaciones (Fraser, 1991; Haney, 2002), tanto las familias como los adolescentes se reconocen como sujetos de intervención con base en una caracterización que determinará qué tipo de atención les corresponde. Para los adolescentes será la privación de libertad hasta tanto se modifique la valoración que los agentes judiciales tienen sobre sus familias. Salvo excepciones, tras el

13 Vale aclarar que en los expedientes no consta ninguna intervención estatal tendiente a incidir sobre estos contextos sitiados por la violencia. 
análisis de expedientes efectuado es posible advertir que si las familias no lograban satisfacer las expectativas que los agentes judiciales tenían sobre ellas, los adolescentes no accedían a morigeraciones en las medidas, aun cuando hubieran tenido buen comportamiento, ausencia de sanciones, etc. Por ello, si bien, idealmente, el joven es el que debe "transformarse", paradójicamente se observa que lo central es que las familias calificadas como "poco contenedoras" se vuelvan "contenedoras" ya que esto es clave para la evolución de la causa.

Para volverse contenedoras, estas tendrán que superar su principal déficit que, según la valoración de los agentes judiciales, es de índole vincular y subjetivo (y no material o social). Construido el diagnóstico con estas coordenadas, no resulta incongruente que, para dicha transformación $-\mathrm{y}$ de acuerdo con las expectativas que se cifran sobre ellas-, el único recurso que se les ofrezca sea un taller grupal para padres. Este encuentro, de dos horas de duración, se realiza todos los meses en una organización social de la localidad y está coordinado por un/a psicólogo/a con el que las familias conversan sobre la experiencia de tener a un hijo preso. De manera notoria, en casi la totalidad de los expedientes, al inicio de la causa, el/la juez/a exige como parte de las reglas de conducta impuestas al joven que sus progenitores concurran al espacio y que, periódicamente, presenten el certificado de asistencia. Solo en dos expedientes constatamos que, además del taller para padres, se gestionó que la familia accediera a una ayuda social material (cuyo tipo, alcance, y duración no se especifica). Asimismo, a algunos progenitores se les exige que tengan tratamiento psicológico, para lo que no se les ofrece ninguna facilidad. En efecto, tal como Patrice Schuch (2009) ha analizado para el caso de la justicia de infancia y adolescencia en Porto Alegre, Brasil, este tipo de acciones componen dispositivos de reorganización de la familia que busca suplir, antes que nada, la "carencia afectiva y moral" que esta tendría según la perspectiva de quienes constantemente la evalúan en este ámbito.

Así, las familias son en su mayoría caracterizadas de manera negativa en tanto, linealmente, se interpreta que su configuración, sus acciones o inacciones, incidieron de manera determinante en la trayectoria de los adolescentes en conflicto con la ley. Al contrario, existen otras explicaciones sociales sobre el delito juvenil -considerado tanto práctica instrumental 
como expresiva-, empíricamente fundadas en nuestro contexto (Kessler, 2004; Miguez, 2010) ${ }^{14}$.

Ahora bien, en un tercer plano del análisis es posible advertir cómo las familias lidian con estas interpretaciones de los agentes y con las expectativas que sobre ellas se generan. Así, en estas negociaciones, la causa se va creando y evolucionando.

Tanto en presentaciones de la defensa, como en los informes que realizan los/as peritos del CTA, en los que realizan los profesionales de las instituciones de encierro, o en las anotaciones que los agentes del juzgado realizan para dejar constancia de novedades y acuerdos con los adolescentes o sus familias, se evidencia que estas, en lugar de ser pasivas o permanecer indiferentes a la intervención institucional, se movilizan para conseguir oportunidades educativas, laborales, opciones alternativas de residencia o asistencia sanitaria para los adolescentes. Es decir, se ocupan de obtener distintos tipos de recursos y ofrecer variadas explicaciones sobre cómo sería la vida en libertad del adolescente para satisfacer las expectativas que la justicia ha generado sobre ellas. En estos escritos se narra que las familias se presentan con certificados de asignación de vacantes, de turnos, con datos concretos sobre en qué días y horarios el adolescente podría incluirse laboralmente en un determinado espacio, así como con propuestas de lugares alternativos de residencia, asumiendo los peligros del entorno en el que residía el adolescente al momento del delito. Asimismo, proponen su inclusión en programas sociales que puedan oficiar de espacio de recreación y referencia. Esta narración particular sobre los recursos ofrecidos por lo general termina con la valoración positiva, negativa o dubitativa acerca de la evolución del adolescente y su familia de quien escribe, y con base en ello puede sugerir, concretamente, la libertad o la continuidad de la medida de encierro.

Además, las familias parecen ser la principal -y en ocasiones únicafuente de recursos de la que se sirven los operadores judiciales (especialmente los defensores) para elaborar estrategias de egreso. De hecho, tal como relatan en la entrevista que realizamos a cuatro defensores

14 Ellos, por su parte, han retomado y rediscutido una tradición de larga data, amplia y diversa, de estudios sociales y criminológicos sobre la delincuencia juvenil, en especial desarrollada en Estados Unidos y posteriormente en Europa, con diversas teorías más vinculadas al positivismo o al interaccionismo simbólico, entre otras. 
del fuero, actuantes en los expedientes relevados, no realizan trabajo de articulación interinstitucional enfocado en los recursos del territorio orientado a diseñar una estrategia de egreso de los adolescentes - por falta de recursos humanos, disponibilidad de tiempo, competencias, o posiciones ideológicas- y por ello exigen expresamente a las familias que sean también responsables de realizarlo. De nuevo, las familias son piezas clave: por lo que efectivamente consigan, y por cómo se pondere su activación en esta tarea.

\section{Los traslados o la dimensión operativa de la desigualdad}

Si las interpretaciones morales de los agentes judiciales sobre las familias orientan con fuerza las formas en que se administra el castigo y la justicia, en el análisis de los expedientes sobresalen aspectos de la práctica rutinaria de la burocracia que también inciden, de manera significativa, en dichas formas. Uno es el relativo a los traslados que habitualmente se requieren para llevar a los adolescentes desde sus lugares de encierro a sedes judiciales para audiencias, evaluaciones o entrevistas con los distintos actores del fuero, así como para atender cuestiones relativas al acceso a sus derechos, principalmente, de salud.

En 10 de los 26 expedientes estudiados constan traslados no realizados debido a falta de móviles, o paro del personal encargado de hacerlos, o incapacidad del área de traslado de la secretaría de niñez provincial de asumir la demanda. En uno de los expedientes, el responsable del área explicaba el incumplimiento al afirmar que solo se llegaba a cumplir el $40 \%$ de la demanda. Ese traslado a la Defensoría, para un comparendo, se realizaría un mes después. Para la misma época, otro joven no pudo asistir a la audiencia en que se dictaría su responsabilidad porque el área de traslado estaba "superada en su capacidad de logística y personal". Otro joven, Pablo ${ }^{15}$, vio reprogramada en cinco oportunidades una audiencia, lo que implicó que la revisión de su medida se demorara cuatro meses. Luego, este mismo joven sufriría la cancelación de su traslado a la sede del CTA en tres oportunidades por falta de móviles, dilatando tres meses más la elaboración de informes centrales para la evaluación de su causa. Si

15 Todos los nombres son ficticios para proteger la identidad de los jóvenes. 
la cancelación del traslado sucede en noviembre o diciembre, los jóvenes deben esperan dos o tres meses para que se reprograme, luego del receso judicial estival. Estas comunicaciones relativas a la imposibilidad de realizar los traslados no parecen originar ninguna reacción ni pedido especial por parte del juzgado más allá de la reprogramación del encuentro no realizado. Pareciera formar parte de una normalidad burocrática con la que los actores se enfrentan y lidian; la cuestionan por lo entorpecedora que es para su trabajo cotidiano, pero que no la vinculan como razón de las altas tasas de prisionalización ni de la extensión infundada de las medidas de privación de libertad. Para ellos, es más una anomalía del funcionamiento burocrático del sistema, que una nueva violación de los derechos de los jóvenes (de su derecho a la defensa material y técnica porque en su mayoría son las audiencias con el juez las que no pueden realizarse, así como tampoco los informes del CTA que serán centrales en las audiencias de revisión de su medida).

Además de dificultar el avance de la causa, los traslados no realizados o demorados impactan en el acceso a la salud. Sumado al carácter habitual, trabajoso y con dilaciones para obtener turnos de atención en dispositivos públicos de salud -que son a los que la totalidad de los adolescentes podía acceder-, dos jóvenes perdieron turnos y sesiones de atención y rehabilitación en un hospital para tratar heridas graves porque no se presentó el servicio de traslado en sucesivas oportunidades. A otro de los jóvenes se le suspendieron sus consultas médicas por falta de traslado.

Si antes exponíamos la dimensión interpretativa del Estado y sus instituciones, los traslados muestran cómo su dimensión material también opera para reproducir prácticas que colisionan con los derechos humanos de adolescentes en conflicto con la ley. La inercia burocrática, la falta de adecuación logística (al tamaño del sistema, a la amplitud de la jurisdicción en cuestión) y también una determinada definición del problema -relativa a los derechos de los adolescentes en conflicto con la ley-deja a los jóvenes privados de la libertad atrapados en una realidad cotidiana en la que no se tiene en cuenta ni el objetivo de resocialización del fuero especializado, ni la proporcionalidad de la pena, ni su eventual morigeración. Estos "imponderables", que a la luz de la saturación empírica parecen más lo habitual que un hecho difícil de anticipar, demoran la resolución de las causas, alargan tiempos de intervención, ralentizan 
un sistema que, de por sí, es bastante poco ágil e impiden la garantía de derechos básicos de los adolescentes. Así producen, con esos desaciertos, una forma de administración particular, una suerte de "amansadora"16.

\section{Las tramas que tejen las causas}

En los expedientes es posible identificar cómo la articulación de niveles de interacción de diversa índole (de definiciones de necesidades, de interpretaciones, de negociaciones, y de burocracias) componen un caso.

Sebastián estuvo privado de libertad 9 meses y 15 días por una causa caratulada como "robo en poblado y en banda" que consistió en el asalto a un camión de zoonosis y el hurto de materiales de construcción de un centro cultural del mismo barrio donde vivía.

El primer informe del CTA afirmaba que la madre de Sebastián, aun siendo consciente de los conflictos que el joven tenía en el barrio, "no hacía nada". Como además el joven declaró consumir drogas y no estar escolarizado, la jueza, al evaluar la situación, ordenó la prisión preventiva del joven con el objetivo de escolarizarlo, tratar sus adicciones y "preparar" a la familia para poder cuidarlo; a sus integrantes, en la misma audiencia, se les ordenó asistir a los talleres para padres. En el argumento para aplicar prisión preventiva solo se leían motivos sociales (falta de escolaridad, de atención a la salud, de "buena crianza"), no riesgos de obstrucción de la causa penal.

Durante el encierro, y según diversos informes que constan en el expediente, la familia se tomó diversas direcciones para contestar la interpretación judicial sobre el modo de implicarse con Sebastián y, así, lograr su libertad. Ante el instituto cerrado en donde estaba alojado, su madre propuso incluirlo en un programa de reciclado y explicó la conveniencia de una ocupación diaria como esa, subrayando que sería más formal que la que tenía al momento del robo: ayudar al padre en el reparto de verduras en el barrio. En paralelo, la familia se involucró en un programa

16 Es decir, encontramos que este proceso tiene cierta familiaridad con aquellos de docilización de los cuerpos que describió Foucault (1988). Estos "imponderables" contribuyen, a través de su repetición, a transformar a los adolescentes en "cuerpos dóciles", mansos, que saben esperar, y a no lidiar, no solo con el aburrimiento que les provoca la privación de libertad, sino también con la incertidumbre. 
municipal que apoya el egreso de instituciones de encierro, presentó ante el juez los certificados de asistencia a los talleres para padres e incluso participó de un proceso de mediación penal sugerido por el juez.

Mientras la familia recorría distintas instancias estatales y no gubernamentales, el tratamiento psicológico y para las adicciones que padecía Sebastián - que el Estado debía garantizar- se demoró meses. Incluso cuando el juez realizó reiterados pedidos al organismo estatal correspondiente para que la atención se efectivizara.

Para cuando Sebastián llevaba seis meses de encierro, el CTA realizó un nuevo informe en el que valoró de manera positiva la implicación de ambos progenitores. La familia que "no hacía nada" parecía haber cumplido las expectativas de los agentes judiciales. Sin embargo, eso tampoco alcanzó. Cuando por fin las evaluaciones fueron positivas, y Sebastián estaba en condiciones de egresar del encierro, la audiencia en la que se le concedería la libertad se postergó en cuatro oportunidades por falta de medios para el traslado a la sede judicial, lo cual demoró cuatro meses la revisión de la medida.

La causa que tuvo privado de la libertad a Sebastián por casi diez meses excedió por completo el hecho delictivo en sí. Se configuró, principalmente, en una trama perversa alrededor de tres dimensiones: primero, de su trayectoria institucional previa al hecho delictivo (su falta de acceso a escolaridad y de atención de adicciones); luego, de la forma en que su familia negoció interpretaciones sobre el cuidado y la responsabilidad filial con el sistema judicial; y, finalmente, del propio padecimiento de la inercia burocrática del sistema penal.

Por su parte, la madre de Gabriel, empleada doméstica, también fue descrita en el primer informe del CTA como una figura adulta que no hacía nada ante la conducta transgresora de su hijo. La causa de Gabriel fue caratulada como "robo agravado con arma de utilería" y si bien, inicialmente, como medida cautelar, se le había impuesto prisión domiciliaria, se le revocó a los pocos días por violarla y presenciar un robo en su barrio. Luego de eso fue privado de libertad por un año y seis meses. Según la interpretación de los peritos, la madre de Gabriel no podía imponer límites ni sostener normas. Además, naturalizaba la violencia, la conflictividad, la transgresión de la ley y el consumo de drogas que existía en el barrio en donde vivían. El informe no hacía referencia 
a acciones que pudiera encarar algún otro actor por fuera de la familia para intervenir en este contexto. La madre fue enviada a los talleres para padres y Gabriel, a prisión. A cada interpretación de necesidades, un satisfactor de los pocos y predeterminados que componen el repertorio institucional en este ámbito.

A partir de allí se evidencia en el expediente la movilización de la madre de Gabriel para torcer la interpretación y cumplir expectativas institucionales por diferentes vías. Por un lado, mediante pedidos del abogado defensor de su hijo, solicitó el traslado del joven hacia otra institución que cumpliera mínimas condiciones de higiene y tuviera posibilidades de recreación. Luego, ante un nuevo encuentro con el CTA, presentó certificados de asistencia al taller para padres y una primera opción para el egreso de Gabriel: había conseguido una vacante en la escuela y podría participar en talleres de oficio en la parroquia del barrio. Estas acciones parecieron no ser suficientes. En cambio, el informe reconoció una mejoría en la situación de contención familiar de Gabriel: el diálogo entre el joven y su padre, con quien no convivía, había mejorado después de la detención.

Mientras las evaluaciones del CTA seguían sin ser auspiciosas, para cuando Gabriel llevaba más de un año en prisión, la madre, orientada por el defensor, gestionó la intervención en la causa de un programa de egreso. Este dispositivo, administrativo y no judicial, podía ser un camino para mediar entre ella y el sistema penal en la medida en que, además de apoyarla para cumplir las expectativas que el sistema tenía sobre ella, podía informar al juez sobre su compromiso y sugerir y avalar la libertad de Gabriel. Se reunió con la coordinación de este programa y argumentó la excepcionalidad del delito ya que nunca nadie de su familia había cometido ningún crimen. Además, enfatizó en que el tránsito por el sistema penal había dado frutos: había implicado una mejoría en la relación de Gabriel con su padre lo que había impactado de manera positiva en el joven; por otra parte, su hijo estaba estudiando, tenía deseos de emplearse como chofer de colectivo y ella procuraba incluirlo laboralmente en una cooperativa de reciclado de residuos cercana a su domicilio. No solo ella y el padre de Gabriel estaban implicados: su abuelo materno 
había ofrecido ayuda para comprar un vehículo para que el joven pudiera trabajar de remisero ${ }^{17}$.

Aunque la mujer había desplegado todo este conjunto de posibilidades, el informe del programa que procuraba acompañar el egreso de personas privadas de libertad, no las validó. Evaluó que estas alternativas laborales "no le permitirían desarrollar relaciones y actividades que le brinden herramientas para una trayectoria futura más estable". Los recursos de la madre no habían sido legitimados y ningún dispositivo le facilitaba otras alternativas "más estables".

Informes, apenas posteriores, dan cuenta de que la madre, perseverante, había propuesto otra salida laboral posible: que Gabriel se incorporara a trabajar en un taller mecánico. Además, había conseguido una vacante escolar para el año siguiente e informaba que ella seguía asistiendo a los talleres para padres. Al final, la negociación tuvo un saldo a favor de Gabriel: le fueron concedidas salidas transitorias cuyas reglas cumplió de manera satisfactoria; tres meses más tarde le otorgaron libertad condicional.

\section{Discusión. Trayectorias institucionales de los jóvenes y sus familias}

Los expedientes que construyen las causas por las que Sebastián y Gabriel fueron privados de su libertad están compuestos en mayor medida por las trayectorias institucionales (Litichever, 2017) de ellos y de sus familias, por las negociaciones de estas últimas con las interpretaciones del sistema penal y por la logística de la burocracia, que por el delito atribuido y por el establecimiento de la responsabilidad mediante una investigación sobre el hecho. Estas trayectorias institucionales, conformadas por condiciones interpretativas y operativas, refuerzan la situación de desigualdad en la que están insertos los adolescentes que tienen conflicto con la ley, al menos, en Argentina. El sistema penal persigue y judicializa, selectivamente, a varones jóvenes de clases populares

17 La ocupación de "remisero" (conductor de un servicio de taxi alternativo que en muchas ocasiones no se encuentra fiscalizado ni regulado) constituye una salida laboral para los jóvenes de escasos recursos ya que no requiere una alta calificación laboral. Solo es requisito poseer el capital necesario para disponer de un autómovil. 
cuyo acceso a sus derechos está altamente restringido. Independientemente de lo que la ley especializada suponga, las causas judiciales se componen de interpretaciones que responsabilizan a los jóvenes y a sus familias tanto de sus propias condiciones de vulnerabilidad, como de las posibilidades de revertirlas. Buena parte de la oferta institucional es encierro para los adolescentes y cierto espacio de maniobra para que las familias negocien estas interpretaciones sin más apoyo estatal que el reconocimiento de necesidades subjetivas que pretenden ser satisfechas con un espacio terapéutico mensual (los talleres para padres). Mientras distintos factores pueden haber incidido en que a Sebastián y a Gabriel se les otorgase la libertad (tipo de delito, tiempo y conducta en el encierro, razones procedimentales, etc.), los expedientes mostraron cómo la activación de las familias según las expectativas del sistema resultó clave para que ello sucediera. Sobre la transformación de las propias prácticas institucionales, ya sean las que deberían procurar el acceso a derechos básicos o minimizar contratiempos logísticos, poco se advierte en los expedientes.

Si se considera el peso que tiene en la causa el resultado de la negociación entre las interpretaciones y los valores morales de los agentes judiciales y de las familias, la ecuación parece resolverse de modo tal que los adolescentes que llegan al sistema penal con un entramado familiar más débil serán los que más sufrirán su dureza y, complementariamente, menos derechos tendrán garantizados. En esta composición particular del caso, tejida entre valoraciones, atribuciones, expectativas y negociaciones, el Estado monta su intervención mediante prácticas rutinarias burocráticas que, además, le imprimen su propia cuota de ineficiencia y perversión, por ejemplo, para la realización de los traslados. Como sutura de todos estos procesos, adviene la decisión judicial -otra particular interpretación- $\mathrm{y}$, finalmente, el destino de los adolescentes.

Al comienzo del artículo, al inscribir la creación del fuero especializado en su historicidad y la separación de las causas sociales de las penales, señalábamos que los argumentos de tal transformación se vinculaban con no criminalizar la pobreza y otorgar garantías procesales a los jóvenes para, sobre todo, evitar la discrecionalidad judicial. Así, el sistema actual 
en Buenos Aires, basado en el derecho penal de acto, buscaría distanciarse de la intervención tutelar o vinculada a la regulación de lo social ${ }^{18}$.

Del análisis de los expedientes se desprende que las relaciones de la justicia penal juvenil con otros componentes del sistema de protección de derechos, cuando existen, son muy débiles y poco formalizadas. Incluso si se considera la situación de vulnerabilidad social de los adolescentes y de sus familias, según las propias caracterizaciones judiciales, prácticamente no constan actuaciones de protección de derechos de niñez, de asistencia social para las familias o de acciones que mitiguen la violencia que signa las relaciones barriales. A su vez, cuando en los expedientes constan intervenciones de programas sociales que podrían formar parte de estrategias de egreso o la sugerencia de su uso (al apuntar a procesos de reinserción social, revinculación escolar o laboral, o apoyos sociales de diversa índole), estos recursos son brindados por las familias y no propuestos por los agentes del sistema judicial que, en general, desconocen su existencia, subestiman o desconfían de su efectividad. En ese punto, parecería que la justicia penal juvenil no actúa como parte del sistema de protección del que, en teoría, es parte.

Una de las explicaciones posibles de la falta de articulación de los sistemas es que este direccionamiento, que procura distinguir las problemáticas sociales de aquellas de índole penal, implique una mirada individualizante sobre el delito juvenil y sus protagonistas. Este énfasis en la capacidad y en la responsabilidad del individuo para gestionar sus propios riesgos y la apelación del Estado a que el individuo se active para hacerlo no son exclusivas del sistema penal sino que impregnan el estilo contemporáneo generalizado de regulación social (Rose, 1996; Castel, 2004; Haney, 2004). Así, la interpretación más extendida en el ámbito judicial sobre el delito juvenil asume que el desistimiento del mismo es fruto de una decisión individual o familiar basada en una evaluación costo-beneficio que tendrían las personas (que los costos del delito son más altos que sus beneficios) que, racionalmente, debería llevarlas a elegir la oportunidad que les da el sistema de "rescatarse" o de ser "una familia

18 Esta centralidad del derecho penal conlleva a una mayor punitividad. Así, al seguir un análisis análogo del caso brasileño, el sistema se perfecciona y por ello se vuelve más "eficiente" en la persecución penal (Fonseca \& Cardarello, 2005). 
contenedora". Esta mirada resulta esquiva no solo a las vulnerabilidades socioeconómicas de los jóvenes y de sus familias y a los condicionantes sociales materiales del entorno, sino también a los simbólicos que operan en intersecciones particulares de clase, edad y género. Además, y fundamentalmente, es ante todo esquiva a la evaluación sobre las propias prácticas y capacidades institucionales y sus consecuencias en las trayectorias de los adolescentes. El sistema administra justicia en función de la capacidad que los jóvenes, y sobre todo sus familias, tengan para adecuarse a expectativas, negociar las interpretaciones que sobre ellos se hacen y soportar los aspectos más perversos de la materialidad del sistema como son, por ejemplo, las demoras de los traslados.

En este punto, la dimensión generacional del análisis resulta clave y paradójica. Es decir, por un lado, la individuación de la salida del delito se materializa en responsabilizar a las familias y colocar al Estado solo como un auditor del proceso y no como garante de derechos. Esta posición emergió del proceso de debates en el que la delimitación de competencias se consideraba el reaseguro para limitar la arbitrariedad penal. Pero, por otro lado, el encierro de los adolescentes como estrategia de "protección" parece aún vincularse con lógicas de predominio tutelar que desconfían de la autonomía de los sujetos y ven en la vida cotidiana de las familias pobres indicios de que "no pueden o no quieren cuidar bien". Así, el debate sobre la necesidad de limitar la discrecionalidad judicial y de reponer garantías, que parecía saldado con la sanción de la nueva normativa provincial, se reflota cada vez y los adolescentes son privados de la libertad para que la familia recapacite y los cuide "bien". Esto sucede aun cuando, para los actores (tanto del poder judicial como del ejecutivo, que despliega políticas territoriales de protección de derechos), esta forma de intervención resulte insatisfactoria.

Así las cosas, los jóvenes se encuentran atrapados en la contradicción de un sistema que, por un lado, dice juzgarlos por el delito cometido (derecho penal de acto) y les exige un comportamiento orientado hacia la búsqueda de autonomía y responsabilización (sin facilitarles herramientas para que lo hagan); pero, por otro lado, decide su destino en función de cómo sus familias logren negociar el dictamen moral que se hace sobre su comportamiento. En el medio de esta forma de administración judicial, propia del gobierno por contradicción (Haney, 2010), 
que funciona encabalgada en un enjambre de interpretaciones disímiles sobre la especialidad, los derechos, el sentido de la pena y el encierro, los adolescentes padecen, además, los efectos perversos de la dimensión operativa de la burocracia. Los impactos tan concretos de las demoras y cancelaciones relativas a los traslados tornan abstracta cualquier referencia a garantías procesales o consideraciones específicas que, en función de la edad, existen sobre la incidencia negativa que el tiempo de encierro supone para un adolescente.

\section{Conclusiones}

En este artículo exploramos cómo algunas condiciones del propio sistema penal juvenil contribuyen a reproducir prácticas que generan altos niveles de encarcelamiento como forma de regular a jóvenes varones que viven en condiciones de pobreza aun cuando, normativamente, procura utilizar la privación de libertad como medida excepcional y por el menor tiempo posible. Mientras, a primera vista, algunos agentes judiciales preocupados, por la alta prisionalización, solo observan escasez de recursos en las familias y en la comunidad para mantener a los jóvenes alejados del delito; entonces es común escuchar que "afuera no hay nada". Un análisis minucioso sobre cómo se configuran las causas en los expedientes judiciales - considerados un artefacto particular para construir realidadespermite iluminar otras cuestiones. Procuramos mostrar cómo las interpretaciones de los agentes judiciales sobre el delito juvenil y sus causas, la arquitectura de necesidades que sobre ellas se monta y el espacio de maniobra generado para negociar estas interpretaciones con los sujetos de la regulación -en especial las familias-, son coronadas por inercias de las prácticas burocráticas y dan forma a intervenciones judiciales que terminan por validar la privación de libertad como el recurso preferido, aunque imperfecto e indeseado, ante la "nada" del afuera. 


\section{Referencias}

Beloff, M. (2004). Los derechos del niño en el sistema interamericano. Buenos Aires: Editorial Del Puerto.

Biebricher, T. y Vogelmann, F. (2012). Governmentality and State theory: Reinventing the reinvented Wheel? Theory \& Event, 15(3), 1-18.

Bourdieu, P. (1998). Espíritu de familia. En M. Neufeld, M. Grimberg, S. Tiscornia y S. Wallace (comps.), Antropología social y politica. Hegemonía y poder: el mundo en movimiento, pp. 37-58. Buenos Aires: Eudeba.

Bourdieu, P. (1994). Rethinking the State: Genesis and structure of the bureaucratic field. Sociological Theory, 12(1), 1-18.

Castel, R. (2004). La inseguridad social. ¿Qué es estar protegido? Buenos Aires: Manantial.

CELS. (2016). Hostigados. Violencia y arbitraredad policial en los barrios populares. Buenos Aires: CELS.

Daroqui, A., López, A. y Cipriano García, R. (2012). Sujeto de castigos. Hacia una sociología de la penalidad juvenil. Rosario: Editorial Homo Sapiens.

Eilbaum, L. (2005). La transformación de los hechos en los procesos judiciales: el caso de los "procedimientos policiales fraguados". En S. Tiscornia y M. Pita (orgs.), Derechos humanos, tribunales y policías en Argentina y Brasil, pp. 131-146. Buenos Aires: Antropofagia.

Fonseca, C. y Cardarello, A. (2005). Derechos de los más y menos humanos. En S. Tiscornia y M. Pita (orgs.), Derechos humanos, tribunales y policías en Argentina y Brasil, pp. 9-41. Buenos Aires: Antropofagia.

Fonseca, C. y Schuch, P. (comps.). (2009). Políticas de proteção à infancia. Um olhar antropológico. Porto Alegre: Editora UFRGS.

Foucault, M. (1988). Vigilar y castigar. Nacimiento de la prisión. Buenos Aires: Siglo XXI.

Fraser, N. (1991). La lucha por las necesidades: esbozo de una teoría crítica socialista-feminista de la cultura política del capitalismo tardío. Debate Feminista, marzo, 3-40.

García Méndez, E. y Beloff, M. (comps.). (2004). Infancia, ley y democracia en América

Latina: Impacto de la CIDN en los sistemas jurídicos latinoamericanos 1990-2004. Bogotá: Temis.

Guemureman, S. y Daroqui, A. (2001). La niñez ajusticiad., Buenos Aires: Editorial Del Puerto. 
Guemureman, S. (2010). La cartografía moral de las prácticas judiciales de los Tribunales de Menores. Los tribunales orales en la Ciudad de Buenos Aires. Buenos Aires: Editorial Del Puerto.

Guemureman, S. (2015). Jóvenes y sistema penal: de las leyes que no fueron y de las leyes que pueden ser. El espejo de Brasil. Voces en el Fénix, (51), 80-89.

Haney, L. (1996). Homeboys, babies, men in suits: The State and the reproduction of male dominance. American Sociological Review, 61 (5), 759-778.

Haney, L. (2002). Inventing the needy: Gender and the politics of welfare in Hungary. California: UC Press.

Haney, L. (2004). Introduction: Gender, welfare and states of punishment. Social Politics, 11 (3), 333-362.

Haney, L. (2010). Offending women. Power, punishment and the regulation of desire. Berkeley: University of California Press.

Litichever, C. (2017). Trayectorias y circuitos institucionales de adolescentes que viven fuera de sus hogares de origen. Entre la escuela y las instituciones de atención a la infancia y adolescencia. (Tesis de doctorado presentada). Buenos Aires: Universidad de Buenos Aires.

LLobet, V. (2013). Estado, categorización social y exclusión de niños/as y jóvenes. Aportes de los debates sobre la exclusión social a los estudios de infancia y juventud. En V. Llobet (coord.), Sentidos de la exclusión social. Necesidades y prácticas en políticas sociales para la inclusión de niños, niñas y jóvenes, pp. 23-50. Buenos Aires: Biblos.

López, A. L. (2010). Proceso de reforma legal e institucional del sistema penal juvenil en la Provincia de Buenos Aires (2000-2009). (Tesis de Maestría). Buenos Aires: Universidad de Buenos Aires.

Lugones, M. (2012). Obrando en autos, obrando en vidas. Formas y fórmulas de protección judicial en los Tribunales Prevencionales de Menores de Córdoba, Argentina, a comienzos del siglo XXI. Rio de Janeiro: LACED, UFRJ.

Martinez, J. (2004). La guerra de las fotocopias. Escritura y poder en las prácticas judiciales. En J. Palacio y M. Candioti (comps.), Justicia y sociedad en América Latina, pp. 203-218. Buenos Aires: Prometeo.

Medan, M. (2014). Distintos mensajes estatales en la regulación de la "juventud en riesgo". Astrolabio, (13), 313-343.

Medan, M. (2011). Sociabilidad juvenil masculina y riesgo: discrepancias y acuerdos entre un programa de prevención del delito juvenil y sus beneficiarios. Última década, 19(35), 61-87.

Mintz, S. (2008). Reflections on age as a category of historical analysis. Journal of the History of Childhood and Youth, 1(1), 91-94. 
Muzzopappa, E. y Villalta, C. (2011). Los documentos como campo. Reflexiones teórico-metodológicas sobre un enfoque etnográfico de archivos y documentos estatales. Revista Colombiana de Antropología, 47(1), 13-42.

Rose, N. (1996). ¿La muerte de lo social? Re-configuración del territorio de gobierno. Revista Argentina de Sociología, 5(8), 113-152.

Saín, M. (2015). El leviatán azul. Política y policía en la Argentina. Buenos Aires: Siglo XXI.

Sarrabayrouse Oliveira, M. (2011). Poder judicial y dictadura. El caso de la morgue judicial. Buenos Aires: Editorial Del Puerto-CELS.

Schuch, P. (2009). Práticas de justiça. Antropologia dos modos de governo da infância e juventude no contexto pós-ECA. Porto Alegre: Editora UFRGS.

UNICEF. (2008). Adolescentes en el sistema penal. Situación actual y propuestas para un proceso de transformación. Buenos Aires: MDS, UNTREF, UNICEF.

Vianna, A. (2010). Derechos, moralidades y desigualdades. Consideraciones a partir de procesos de guarda de niños. En C. Villalta (org.), Infancia, justicia $y$ derechos humanos, pp. 21-72. Buenos Aires: UNQUI Editorial.

Villalta, C. (2004). Una filantrópica posición social: los jueces en la justicia de menores. En S. Tiscornia (comp.), Burocracias y violencia. Estudios de antropología jurídica, pp. 281-326. Buenos Aires: Antropofagia.

Villalta, C. (2010). La administración de la infancia en debate. Entre tensiones y reconfiguraciones institucionales. Estudios en Antropología Social, 1(2), 81-99.

Villalta, C. (2013). Un campo de investigación: las técnicas de gestión y los dispositivos jurídico-burocráticos destinados a la infancia pobre en la Argentina. Civitas, 13(2). 245-268.

Villalta, C. y Llobet, V. (2015). Resignificando la protección. Nuevas normativas y circuitos en el campo de las políticas y los dispositivos jurídico-burocráticos destinados a la infancia en Argentina. Revista Latinoamericana de Ciencias Sociales, Niñez y Juventud, 13, 167-180. 